This item was submitted to Loughborough's Research Repository by the author.

Items in Figshare are protected by copyright, with all rights reserved, unless otherwise indicated.

\title{
Reference recalibration repairs: adjusting the precision of formulations for
} the task at hand

PLEASE CITE THE PUBLISHED VERSION

http://dx.doi.org/10.1080/08351813.2012.674190

PUBLISHER

(C) Taylor \& Francis Group

VERSION

AM (Accepted Manuscript)

LICENCE

CC BY-NC-ND 4.0

REPOSITORY RECORD

Lerner, Gene H., Galina B. Bolden, Alexa Hepburn, and Jenny Mandelbaum. 2019. "Reference Recalibration Repairs: Adjusting the Precision of Formulations for the Task at Hand". figshare.

https://hdl.handle.net/2134/15261. 
This item was submitted to Loughborough's Institutional Repository (https://dspace.lboro.ac.uk/) by the author and is made available under the following Creative Commons Licence conditions.

\section{creative
commons}

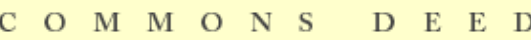

Attribution-NonCommercial-NoDerivs 2.5

You are free:

- to copy, distribute, display, and perform the work

Under the following conditions:

Attribution. You must attribute the work in the manner specified b the author or licensor.

Noncommercial. You may not use this work for commercial purposes.

No Derivative Works. You may not alter, transform, or build upon this work.

- For any reuse or distribution, you must make clear to others the license terms of this work.

- Any of these conditions can be waived if you get permission from the copyright holder.

Your fair use and other rights are in no way affected by the above.

This is a human-readable summary of the Leqal Code (the full license).

\section{Disclaimer 만}

For the full text of this licence, please go to: http://creativecommons.org/licenses/by-nc-nd/2.5/ 
Reference Recalibration Repairs:

Adjusting the Precision of Formulations for the Task at Hand

Gene H. Lerner • Galina B. Bolden • Alexa Hepburn • Jenny Mandelbaum 


\begin{abstract}
This report examines what is involved when a speaker overtly selects one formulation over another by employing a repair operation that reformulates a reference in a way that adjusts or recalibrates it, rather than abandons the original reference altogether. Focusing primarily on references to persons, we show that beyond the narrowing of a reference-increasing its precision - that results in an improved fit between a person reference and other components of a turn-at-talk, these reference recalibration repairs can be used to do such things as meeting the requirements of a story's telling, upgrading the credibility of an information source, and justifying a rejection. This ties speakers' overt concern with calibrating a categorical reference to the formation of action in their turn-at-talk. By contrast, we then show how broadening a reference - decreasing its precision - can be used as a method for displaying uncertainty and thereby recalibrating a reference to fit the manifest knowledge state of the speaker (or a recipient).
\end{abstract}

Key words: person reference, self-repair, ascribed action, action formation, granularity 
Reference Recalibration Repairs: Adjusting the Precision of Formulations for the Task at Hand

In some of the earliest work on the operation of Membership Categorization Devices, Sacks (1972a, 1972b, 1992) observed that because there is always more than one correct category to choose from in selecting a way to refer to a person categorically, the use of one or another membership categorization device by a speaker cannot be based simply on its correctness. The import of this is that in selecting from among multiple correct possible ways of formulating any particular reference, a speaker can employ another criterion: its situated relevance. The situated relevance of one membership category over another can be found in the production and treatment of categories as accounts for action based on their connection to “category-bound actions" and in their “inference-rich" character (Sacks, 1972a, 1972b, 1992). Furthermore, there is evidence that formulations of many kinds can also be selected for their situated relevance, including formulations of time, place (Schegloff, 1972), objects, events - and even including the manner in which a speaker characterizes an action in ascribing it to a person. Formulation selection is part and parcel of the formation of the action in a turn at talk.

One far-reaching consequence of this for turn construction and for turn constructional unit (TCU) composition in particular is that various kinds of formulations - especially formulations of references to persons - and action ascriptions may be conjointly selected by reference to what a speaker is accomplishing in and as their turn at talk. For example, a person reference and an action ascribed to that person, when produced as constituent features of a description in a story's telling, can be co-selected based on their conjoint relevance for the telling. ${ }^{1}$ 
As Lerner and Kitzinger (2007) have demonstrated, one way to expose how speakers select formulations from among alternatives (by reference to their conversational surroundings) is to examine those places in conversation where a speaker treats a formulation as a source of trouble insofar as they suspend the forward progress of their turn and then repair that just-voiced formulation. On some occasions the repair of a reference to a person can change the referent and thus can be understood as simply correcting a misidentified referent, as in Extract 1.

\section{Extract 1: NB}

$1 \quad$ A: $\quad$ And Bill- an' Bud got do:wn.

2 B: $\quad$.hhh Yes.

Yet on other occasions the speaker is not correcting a misidentification, but rather can be understood as changing the manner in which they are referring to the same referent, as in Extract 2. Here, "feller" is replaced by "man" but the repair solution - the reformulated reference refers to the same person.

\section{Extract 2: TG:6}

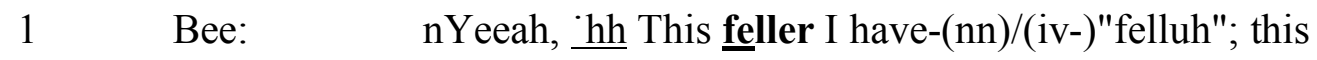

In this case, the manner in which a membership category is formulated changes, but the referent does not. Moreover, the replacement ("man") retains the same level of categorical specificity as the original formulation ("feller") in that it can be understood as part of a corresponding collection of categories. 
In this report we consider reformulations that adjust the precision or scope of a formulation without abandoning the original referent altogether. Here repairing the original formulation can be understood as recalibrating the reference, as the interviewer does in Extract 3 (line 8). In this radio interview, Lynndie England, a former prison guard in Iraq, is being interviewed about the abuse of the inmates. In this case, the interviewer first employs a gender category ("men") to refer to the prisoners at line 6 (as England had done at line 3 with "guys"), and then replaces this with a setting-specific category, "detainees" (line 8) to refer to the same referent. The setting-specific category (“detainee”) derives from a different membership categorization device and adds the relevance of the interviewee's own institution-specific identity as a prison guard to her already relevant identity as a woman.

\section{Extract 3: BBC World Service "Outlook" 2/4/09}

\begin{tabular}{|c|c|c|}
\hline 1 & England: & But the:y $>$ like I said $<$ the first time I went over \\
\hline 2 & & there ins- (1.0) was on that cell block:. There was \\
\hline 3 & & already gu::ys there that- (.) were already stripped \\
\hline 4 & & down en na:ked. (.h) \\
\hline 5 & & $(0.2)$ \\
\hline 6 & IR: & Didju not fee::1 (0.4) sorry for the men. \\
\hline 7 & & $(0.5)$ \\
\hline 8 & IR: & For the deetainee:s. \\
\hline 9 & & $(0.5)$ \\
\hline & IR: & Being forced to do such humiliating things. \\
\hline & & $(5.5)$ \\
\hline 12 & England: & I'm not gonna answer that question. \\
\hline
\end{tabular}


Here repair seems to be employed in pursuit of a response (after no uptake was forthcoming at line 7), but the form the reformulated reference takes is tailored to the action of the turn. This reformulation can be understood as increasing the precision of the reference because it increases the specificity of the domain of actions bound to the referent and the inferences associated with it. $^{2}$ Here, increasing the precision of the formulation brings the interviewer's action into sharper focus. The repair solution (“detainees") is more closely tailored to the thrust of the interviewer's question, and to the criticism that question may embody given its "negative interrogative" format (Heritage, 2002). By making relevant a setting-specific membership categorization device (one that involves a membership category from a team-type membership categorization device), the interviewer's question can be understood as addressed to the interviewee as a former guard, and not only as a woman, and as such draws a direct line of culpability from the prisoners to her (now coupled with the further degradation incurred by her gender vis-à-vis the men in her charge).

It is this repair-enabled recalibration of references to persons that we consider in this report. Our investigation of reference recalibration takes inspiration from Schegloff's (2000) examination of the operation of "granularity." He points out, "calibrations and shifts of granularity are common and central features of accounts given of courses of action" (Schegloff, 2000, p. 718, note 2). ${ }^{4}$ However, our investigation locates a distinctly different domain for granularity calibration. Rather than examining practices associated with 'doing describing' as Schegloff is most centrally concerned with, we focus on practices employed in formulating references to persons. By concentrating on instances that involve reference recalibration repair, we can present direct empirical evidence of a speaker's overt orientation to calibrating a formulation. This is a site where the scope or specificity or precision of a formulation - that 
which we consider akin to granularity for this domain - becomes available through its explicit re-calibration, because it is here that speakers suspend the further development of the emerging turn and/or sequence in order to narrow or broaden the terms of the formulation. Schegloff (2000) notes that understanding how interactants manage granularity is part of the puzzle of understanding how social knowledge is organized and deployed. In this report we put forward one piece of the solution to Schegloff's puzzle regarding the deployment of social knowledge bound to categorical forms of reference. We do so by first describing some of the features of reference recalibration repair and then by showing what these repairs can be employed to accomplish in talk-in-interaction. Next we report on the operation of recalibration repair beyond reference to persons, and finally we show that the two forms of recalibration repair -narrowing and broadening a formulation - are not symmetrical alternatives that only differ in the direction of their recalibration, but are composed differently and are employed to implement completely different orders of action.

\section{Directionality}

We begin by observing that reference recalibration can result in a repair solution that either narrows the scope of a formulation or broadens it. In Extract 3 (above), the repair solution ("detainee") narrows the scope of the reference and thereby sharpens its relevance for the task at hand. By contrast, in Extract 4, the repair broadens the scope of the reference (from "anaesthetist" to "doctor"; lines 3-4), and in doing so somewhat weakens the referent's authority (as a specialist) and thereby the authoritativeness of the conclusion the speaker is attributing to that person's report.

\section{Extract 4: $\mathrm{BCC02}$}


1 Brenda: I can't afford to pay pris:vately .hhhh but what they

2 have done is got an independent report from an

anaesthetist, .hhhh U:m An' this anaesthetist:

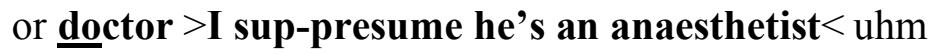

has said .hh that's it's not necessarily the epidu:ral

In this case the reduced speaker certainty such broadening recalibrations can intimate is then made explicit in the aftermath of the repair completion (line 4). (We will have more to say about this extract towards the end of the report.)

\section{$\underline{\text { Repair Operations }}$}

As a second observation, we can note that speakers implement these repairs in a number of different ways. For example, recalibration repairs can be implemented by completely replacing one formulation with another formulation with a different degree of specificity, as in Extract 5. ${ }^{5}$ In this case (taken from a radio interview), a replacement operation is employed in an environment in which the category-bound import of "knowing" (line 6) has been left inexplicit by the use of "people".

\section{Extract 5: BBC World Service "Outlook" 11/4/10}

$1 \quad$ WLY: We:: hnh (0.4) because: of my fa:thers: position, $=$ as a political prisoner, $=$ 
8 WLY: Well without thee: hh the secret $(0.2)$ poli:ce knowing. .hh All of the work of explicating (or contextualizing) "knowing" as having category-bound import is carried by the repair solution itself ("the secret (0.2) poli:ce"; line 8). This recalibrated categorical reference brings into focus both the person reference and the import of the ascription of "knowing" for that category of persons. The fit is established reflexively in that the speaker furnishes a categorical reference and in doing so materializes the import of an ascribed "state of awareness" that was not otherwise specifically bound to that category.

By contrast, reference recalibration can also be implemented by adding something to the original formulation. ${ }^{6}$ The result of this operation - the repair solution that results from inserting a new element into the TCU and thereby replacing one reference form with another - retains some features of the original formulation, but modifies it in a way that adjusts the precision of the reference, as in Extract 6 . Here we see how a speaker explicitly deploys ethnic identity as a method of legitimization.

\section{Extract 6: BCC999}

1 Pam: I haven't had any problems for [two yea]:r[s.]

2 Clt: [Na:h. ] [Th]at's wonderful.

4 Pam: A:nd uh I have this u:h this chap this: Islamic chap who:'s 5 into: Yunani medicine and $[(\quad)]$

6 Clt: [个Ooh. That] sounds interesting.

Pam adds "Islamic" to a second saying of the already delivered phrase "this chap" (line 4) while shifting the stress from "chapp" to the newly added "Islamic." This modification of the reference 
adds legitimacy to the referent in that the form of medicine connected to this person can be associated with Arab and Persian practices.

In replacing or modifying the trouble source term, reference recalibration repairs can establish distinct relationships between the original formulation and the recalibrated reference. So, for instance, the repair solutions in Extracts 3 and 4 (above) refer to the same referent as the original reference, even though the scope of the reference has been changed; it has been narrowed in Extract 3 and broadened in Extract 4. In other words, although the repair has recalibrated how a person is being identified, who is being identified does not change.

By contrast, in Extracts 7 and 8 below recalibration (again narrowing and broadening the original formulations, respectively) does not result in a reference to the identical referent. These repairs change the scope of the reference in a manner that also amends the referent. In Extract 7, the category "women" is explicitly extracted from "people" in a way that excludes the other membership category of the same collection (“men").

\section{Extract 7: WH 080211}

$1 \quad$ JM: .hhh Now- (.) many people (0.2) \#well\# (th)at maybe jus- (.) many women do have a (0.2) complex relationship (.) with footwear.

Whereas, in Extract 8 the repair is carried out in a manner so as to show that the repair solution is an aggregation that encompasses both the original referent ("women") as well as the other (never-mentioned) membership category from the same collection (“men"). ${ }^{7}$

\section{Extract 8: BBC Radio 4, Women's Hour 8/10/07}

1 IR: What about women who: $>$ or $<$ people actually. hhh 
In both Extracts 7 and 8 the repair segment is composed in a fashion that shows the referent is being amended.

Finally, in Extract 9 we find another way a repair solution can be related (by its speaker) to the original formulation; here the recalibrated reference is extracted as a representative or example of it. In this case an evidently problematic reference-in-progress to "people from [a place]" is repaired by way of categorical exemplification (as a way of explaining an orchestra name change).

\section{Extract 9: SBC 19}

1 RON: What's the symphony called ${ }^{\circ}$ here $\iota^{\circ}$

2 FRANK: We.:1l they call i- useta be Twin Cities.=I think they call't

$4 \quad \mathrm{RON}: \quad \mathrm{H}[\mathrm{m}$

5 BRETT: $\quad[$ They do:. eh- $=$

6 FRANK: =Because they draw a lot of people from (.)

8 RON: $\quad=$ Mhmm:

10 RON: Who play in it. 
12 RON: $\quad$ you mean?=

13 FRANK: =Yeah. who play in it.

The repair solution offers an exemplification that includes the membership category "music teachers," thereby making clear who "people" (line 6) refers to - i.e., members of the orchestra, not members of the audience. This extract exhibits how an unrevealing or undifferentiated formulation ("people") can be employed to refer to a determinate membership category through the action ascribed to it, as well as the trouble to which this reference practice is vulnerable. Note that, following the self-repair, a recipient (lines 10 and 12) directly addresses the trouble that can be found in "they draw a lot of people from" as possibly referring to where the audience members (versus the musicians) are drawn from.

\section{"Two-Step" Recalibration}

Recalibrated references can themselves be further refined through a "two-step" repair procedure (see Lerner and Kitzinger, 2007), as in Extract 10. This instance is taken from a radio program in which Julie is being interviewed about the effects of divorce on children. At lines 2 4 Julie introduces an example in support of her claim at line 1. The first step in recalibrating her reference is the extraction (line 2) of "a boy" from the encompassing category "children" (most proximately denoted by "They"). (Here the speaker also shifts to a single member of the category, thus allowing her to ascribe (category-bound) actions to a single representative, rather than to the category as a whole.) On a second try (the second step) the speaker then adds a further categorical constraint ("six year old"; line 3). This extracts an even more tightly circumscribed stage-of-life category ("six year old boy"). Actions are then explicitly ascribed to the narrowed composite membership category ("six year-old boy"). 


\section{$\underline{\text { Extract 10: Radio } 4}$}

1 Julie: $\quad$ Because children don't hea:r the words necessarily

2

3

4

5 Pre:

6 Julie:

7 Pre:

8 Julie:

9 at the beginning. .hh They're quite likely- a boy

six year old boy's quite likely to go off and play football

.hh or watch the telly and look as if he hasn't hea:rd.

Because they simply ca:n't [ c o m p u:te. ]

[They don't want] to::=

$=$ They don't [want to.]

[Or they ] can't compute o:r or it's

just (.) too horrificic.

The activities the speaker ascribes to the referent can be understood as category-bound to the recalibrated reference ("a six year old boy"). As such, the recalibrated reference contributes to what is being done in the turn: the speaker is building a case for why children (members of the encompassing category) react to divorce in the ways they do - that is, by being children. The reference is tailored to the actions that can be convincingly bound to that category: It is not just children, not just a boy, but "a six year old boy" who would self-evidently rather "watch the telly" and "play football" than discuss his feelings about his parents' divorce. "A six year old boy" is an inference-rich membership category, and the speaker relies on (or perhaps even reflexively materializes) members' commonsense understanding of (stereo)typical behaviors and attitudes attributable to it. Note that both speaker and recipient return to "they" in producing the upshot (lines 5 - 9) thereby treating the "six-year old boy" and the actions ascribed to him as representative of the encompassing category "children." Having described some features of 
reference recalibration repair, we now turn our attention directly to how these repairs are employed in action.

\section{Reference Recalibration Repair in Action}

We now concentrate on what can be accomplished through reference recalibration repairs, starting with repairs that narrow the original formulation in some way and then turning to the special case of repairs that broaden the original formulation. In many, even most (but not all) cases of reference recalibration repair, a person reference term is repaired in a way that results in a reformulated categorical reference that seems more attuned to the actions, attributes and setting depicted in the talk. Note that such "categorical tailoring" of a reference term is not an automatic result of reference recalibration repair, as such repairs could conceivably result in a reformulation that reduces the scope of the original formulation, but is not linked directly to the business of the turn. Categorical tailoring of a person reference in selecting a recalibrated formulation draws on the inference-rich character of membership categories as employed in conversation. Speakers can refine a reference by shifting to an inference-rich or more-inference rich membership category that carries with it actions and attributes that can be linked to the repair solution; moreover, these recalibrated categorical references can make relevant a particular collection of categories as well as any relational connections between categories in that collection. We first consider cases where it seems that reference recalibration repair is employed simply to repair a problem in referring; we then turn to cases in which the recalibration seems to be involved in doing more than repair - where it seems to be involved in the formation of the action implemented through the speaker's turn-at-talk. 


\section{$\underline{\text { Reference Recalibration as "Repair Simpliciter" }}$}

A reference recalibration repair may be occupied with clarifying a potentially ambiguous or confusing reference and nothing more (cf. Schegloff, 1996, on "reference simpliciter"). For instance, it can be employed as a solution to a "tandem reference" problem: the problem of referring to one set of persons in connection with another set of persons using the same reference term for both sets of persons. In Extract 11, while discussing news about a recent earthquake, Jeanne (lines 8 - 10) begins to formulate the principal characters of her story as "Some of the people [that are trying to get people out of there]", but then replaces "people" with a membership category ("workers") that is tailored to the action she is about to ascribe to them, before completing the formulation. In so doing she differentiates one set of people (earthquake victims or survivors) from another set of people (rescue workers) and avoids using the same term for both.

\section{Extract 11: Marie \& Jeanne}

1 Jeanne: O:h. I heard (something) in:teresting.

2

3 Marie:

4 Jeanne:

5 Marie:

6 Jeanne:

7 Marie:

8 Jeanne:

9
(.)

hWha' wz tha:t.(( $\left.\mathrm{y}\left[\begin{array}{llllll} & \mathrm{a} & \mathrm{w} & \mathrm{n} & \end{array}\right)\right)$

[Wel- on the: collapsd bridge?]

Uh hum.h[hhhhhhhhhhhh ]

[there?(.)the: freeway part?]

Yeh- u- oh- the [bri : d ge . ] Yeah. ]

[Some of the pe]ople tha]t- (.)

Some of the (0.2) wor wo:rkers that are:-

that are trying to get people ou' there? 
11 Marie: Oh. That's the freeway,[yeah

12 Jeanne: [(right)

13 (.)

14 Jeanne: Yeah. $=$ so they felt (0.4) a mo:ving ha::nd.

15 Marie: Uh hum, hh

Notice that "some of the people" (line 8) is produced in overlap with the last part of another speaker's utterance. Here, the post-overlap opportunity to recycle the overlapped turn beginning (Schegloff, 1987) is employed to circumvent the use of the same term to refer to the other set of persons. Thus the speaker differentiates one set of people from the other by shifting to a category fitted to the action she is about to ascribe to the first set of people. It is this action that connects "the workers" to victims or survivors. In this case reference recalibration seems simply aimed at repairing one kind of reference problem (tandem reference), and does so in a way that is tailored to the description. Nevertheless, note that merely differentiating the two sets of persons does not require a repair solution fitted to the ascribed action.

In Extract 12 (line 8) the membership category "prisoners" replaces "people.” In this case it seems pretty apparent that "people" refers to those who occupy the "two hundred be:ds" (i.e. "prisoners"), but this connection is initially left tacit, leaving open the possibility (even if only as a "theoretical possibility") that, for the recipient, "people" could possibly be (mis)understood as subsuming other categories of persons at the prison (e.g. guards, visitors, cleaners, etc.) or as indeterminate.

\section{Extract 12: NPR 11/16/09}

1 A: As a- a maximum securidy prison,. hh

2 has sixteen hundred saye: 11 , .hh uh::: 
3 bud it's barely u:sed, there's a- a

$>$ mi $\uparrow$ nimum securidy section here $<$ an that's

what the state has been $\underline{u}$ :sing. $=I t$ has

about two hundred be $:$ ds $=$.hh Uh: on av'rage

there'r abouda hundret fordy four: .hh

<people here a day.>=prisoners here a $\downarrow$ day,

.hhh a:nd uh::: it's uh: so unused=that's

why uh officials here really push for the

federal government to take some a:ction .

In this way, "people" can be understood as possibly underspecifying the referent, whereas the repair solution - the recalibrated reference "prisoners" - makes the membership category explicit by naming it. This suggests to us that a (preferred) solution to the non-recognitional reference problem is a membership category that is explicitly tailored to the turn's talk in one or more ways: most prominently it can be tailored to the action ascribed to a referent in the turn or to the setting the speaker is describing, or both. Categorical tailoring itself can be understood reflexively as an account for repair in that it results in a comparatively better fitting formulation.

Repairs such as Extract 12 suggest that "people" (and perhaps other less-than-fitted formulations) can be treated as a source of trouble solely because they are not tailored to the setting and action ascribed to the referent. Even in cases where there seems to be virtually no chance of misunderstanding, speakers may still employ a reference recalibration repair that tailors the reference to more closely fit the actions ascribed to the person and to the setting, as in Extract 13 from a birth crisis helpline.

\section{Extract 13: BCC}


1 Ann: But that's quite common. Hysteria.

2 Clt: Ye:s. I'm afrai:d, you know, people-women don't get the kind of care. hh the one $=$ to $=$ one care thet they need after childbirth. Note that recalibration repairs that narrow the scope of a reference (as in Extract 13) are ordinarily produced without explanation, whereas (as we shall show) those repairs that broaden the scope of a reference recurrently include features that account for the repair. Broadening a formulation seems to be an accountable action insofar as it produces a (comparatively) less fitted formulation, whereas narrowing apparently accounts for itself because repairs that engage in categorical tailoring result in a formulation that achieves co-selection of the constituents of the TCU. Although reference recalibration repairs that reduce the scope of a formulation may be employed simply to repair an ambiguous or even an ill-fitting reference, this practice can be exploited to accomplish more than repair, as we show in the following.

\section{Meeting the Requirements of a Story's Telling}

Here we consider how reference recalibration repair can be used in the service of story telling. In Extract 14 (below) we see, in quick succession, two repairs in which relational membership categories are employed as repair solutions in the course of telling a story (lines 3 and 8). In each case, the speaker first employs "people" (as or in a reference to persons in a location) and then performs a recalibration repair. It is the second instance - in which recalibration is employed to lay the basis for a reported surprise - that we focus on in this section.

A brief sketch of what is going on in this conversation is required before we can proceed. Carrie and Skip are speaking on the phone in the aftermath of the recent death of Carrie's 
husband. Earlier in the conversation (data not shown), Carrie reported to Skip that she received a "very nice" condolence letter from Philip Hammond, a co-worker of her deceased husband. She then reports the lengths to which she went to let other co-workers know about the death, but complains that Philip Hammond is the only man at her late husband's workplace (in Norfolk) from whom she has heard. She reports that she "thought of" letting Philip Hammond know, implying that she had not in fact done so. Then, for about three minutes, talk turns to how Carrie is managing in the aftermath of the death, before she resumes her account of from whom she has heard ("one or two people in Norfolk.=frie:nds"; line 3). ${ }^{8}$

\section{Extract 14: Holt:88U:2:4(1):24}

1 Car: 'anywa:y, ${ }^{\circ}$ hh[ But we've ]heard fr'm one'r t- $\mathrm{I}$ heard from=

2 Ski: [BU'WHAT-]

3 Car: $\quad=$ one ' $r$ two people $\downarrow$ in Norfolk.= frie:[nds

$4 \quad$ Ski:

[Oh had you. $=$ ye:s,

5

$\underline{h} h h[h \underline{h}$

6 Car: ['nd as I said I wz surprized th't- Well you see we put

7 it in the Eastern Daily Pre:ss.= the announcem' $n$ ' ' $n$ then

8 hh that wz the quickest way of letti[ng people kno:w]=

9 Ski: $\quad[$ i h Y $\mathrm{Y}$ e : s. $]=$

10 Car: =sort'v acquaintances,

11 Ski: lgihYe:[s

12 Car: $\quad$ [An:d Philip Hammon[d $\uparrow \underline{\text { saw }} \downarrow$ it. ('n'ee)]=

13 Ski: $\quad[. h h h h h \underline{h h h}]=$

14 Car: $=[($ an'ee wrote a ve $]$ ry nice[ $\downarrow$ letter $)$. 
Carrie indicates (with "and as I said" at line 6) that she is returning to something previously mentioned on this topic. She indicates a surprise ("I was surprised th't-") and then aborts the TCU before the projected surprise is voiced. In its place she produces an explanation of the circumstances that led to the surprise ("Well you see..."), reporting that they placed a death announcement in a local Norfolk newspaper. (Note that the speaker now resides across the country from Norfolk.) She is apparently about to report a consequence of this ("and then"; line 7), but again aborts this next story element and instead furnishes an account for why she placed an announcement in this newspaper: "that wz the quickest way of letting people kno:w" (line 8). Skip interjects an early (recognition point) uptake at line 9, perhaps showing that he accepts the account unhesitatingly, yet at line 10 Carrie increases the specificity of the reference "people" to "sort 'v acquaintances," before reporting, as the punch line of the story, who actually saw it: “An:d Philip Hammond $\uparrow \underline{\text { saw }} \downarrow$ it” (line 12), thereby explaining how he had come to write a letter of condolence.

In recalibrating the reference from "people" to "acquaintances" Carrie more precisely formulates for whom the newspaper death announcement was intended - and does so in the service of the story she is telling. (In this second occurrence "people" is also in a sense formulated, albeit indirectly, by reference to a location: in effect, "people who have the opportunity to read the Eastern Daily Press announcements"). The repair solution makes available - through the collection of "notification-relevant categories" and their inference-rich character (Sacks, 1992, Vol. 1, pp. 40-41) - the story-relevant contrast between the intended recipients of the notice ("acquaintances") and who (thereby) could have unexpectedly seen it: that it was an incumbent of a different notification-relevant membership category - a co-worker of her husband's - who saw and responded to the announcement. ${ }^{9}$ Further, it is possible that this 
repair may also be oriented to the just-completed repair in which "people" gives way to "friends" ("one 'r two people in Norfolk.= friends"; line 3). Reporting that she put the announcement in a local Norfolk newspaper could make the formulation "people" vulnerable to being heard as a locally subsequent reference and thus that she took it that the newspaper is a proper way to notify friends - or at least as not excluding friends, since it is from friends that she has so far reported hearing. And this, of course, would further defeat the contrast that is needed to serve up Philip Hammond's letter as surprising.

The reference recalibration repair (line 10) brings into focus the coincidence that the story is designed to report: a newspaper announcement of her husband's death intended for acquaintances was seen by an incumbent of a category for whom it was not intended: one of her late husband's co-workers, Philip Hammond, and yielded (as Carrie has explained earlier) the only condolence letter she received from his co-workers, despite her concerted attempts to notify the co-workers by phone at the time of his death. Here again a speaker tailors a formulation to the task at hand by replacing a reference that does not specify a membership category with one that does. In recalibrating the reference from "people" to "acquaintances," Carrie reveals her own "membership categorization analysis" by exposing in practice her orientation to an (ascribed) action-relevant collection of categories and the inference rich character of those membership categories (for the action she has ascribed to herself in the story).

Extract 15 shows that employing reference recalibration repair can also be done in the service of setting the scene for an upcoming story. Here, Maya is talking about her family's trip to New Orleans. At line 3, she begins to describe the scene she and her husband encountered by first reporting seeing "a lot of people" ("nar:o:,du palno"; also translatable as a "a big crowd"). When she reaches a possible completion of this TCU, she suspends the forward progress of her 
turn to reveal what sort of "people" they saw: "youngsters" ("maladëzhi"; line 3). This reformulation introduces a story-relevant "stage of life" into the telling.

\section{Extract 15: RP 31 (Russian)}

1 MAY: Vo:t/=A pat ${ }^{\wedge}$ om pashli s nim guljat'./ PRT and then went with him walk Then we went for a walk with him ((in reference to her husband))

2 RIM: $\mathrm{Mm} \mathrm{hm,/}$

3 MAY: Nu i *smo 'rim cheta nar:o:,du palno/ maladëzhi tam va-* PRT and look something people many youth there We look and see a lot of people/ youngsters there vakrug adnavo zdanija/ $((*$ expressive breathy voice $))$ around one building around one building

5 RIM: $\mathrm{Mm} \mathrm{hm}$,/

6 MAY: I stajat ma,l'chiki naverxu/ i kidajut eti vot hhh prashël and stand boys upstairs and throw these PRT passed And there are boys standing upstairs and they're throwing these eh a festival zhe tol'ka karnava:?,1/ [i tam vezde:,/ na pravada:, $\mathrm{x} /=$ PRT just festival and there everywhere on wires just ended/ and everywhere, on powerlines,

8 RIM: $[\mathrm{M}-\mathrm{hm}, /$

$9 \quad$ MAY: $=$ na dere, $\mathrm{v}$ ”jax vot eti busy iz bintov./ on trees PRT these necklaces from gauze on trees, there are these gauze necklaces

10 RIM: $\mathrm{Mm} \downarrow \mathrm{hm} . /$

12 MAY: I kidajut./ and throw and \{they are throwing \{them ((i.e. the boys are throwing the necklaces)) 
((25 seconds omitted: their son joins them and explains the situation))

13 MAY: > Zn`chit< mal'chiki sve:rxu ukazyvajut na devachku,/

meaning boys upstairs point to girl

Boys from upstairs point to a girl

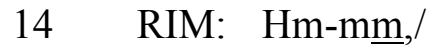

15 MAY: Devachka (v)padnimaet koftachku,/

girl raises shirt

The girl raises her shirt

$16 \quad$ RIM: $\mathrm{H}[\mathrm{m}-\mathrm{mm}$

17 MAY: [Ona bez tapov pan(h)im(h)ae bez etix/ [£bez $\{$ bra $\} £ /$ she without tops understand without PRT without bra

She's not wearing a top you see without uhm without $\{\mathrm{a}$ bra $\}$

18 RIM:

[Ojheh-heh-heh .h

19 MAY: $\uparrow \mathrm{Nu}$ vobshem nu voschem $\{\underline{\mathrm{fu}}\}$ -

PRT generally PRT generally fun

So generally it was $\{$ fun $\}$ -

The reference recalibration (from "people" to "youngsters") allows the teller to present the scene as it temporally unfolds to her as an observer: first, they (the teller and her husband) see a crowd of people and then discover them to be "youngsters". Recalibration repair is employed in the service of the telling about an event that gradually reveals itself to the teller and prepares the reference for actions now accountably associated with youth. The reformulation is subsequently used as a basis for referring to the scene's participants as "boys" (lines 6 and 13) throwing necklaces at "girls" (line 13). And, thus, "stage of life" is further differentiated by gendered categories and the actions that obtain between them as both fitted to their stage of life and between their genders. Furthermore, "youngsters, boys and girls" as categorical formulations are better fitted to the description of the "fun" scene (line 19) being described: a scene that involves the girls lifting their shirts to entice the boys to throw necklaces to them. Moreover, by 
specifying the stage of life, the teller (who is middle aged) presents herself (and her husband) as (unsuspecting) outsiders to what is going on.

\section{Upgrading the Credibility of an Information Source}

Pomerantz (1984) notes that speakers are concerned with sourcing their claims when there is possible doubt about the claim's veracity and that some information sources are treated as more authoritative and reliable than others. Reference recalibration repair can be used to upgrade the credibility of a source of reported information - and thereby increase the authenticity of the information.

Extract 16 comes from a call to a child protection helpline. The caller is reporting the circumstances of a neighborhood seven-year-old girl she has been trying to help, complaining about inadequate assistance from Social Services. The caller replaces the less-than-authoritative reference to "people" with the categorical reference "neighbours," (line 8), thereby upgrading the credibility of the source of corroborating information by fitting a reference to an ascribed action in order to account for that action.

\section{Extract 16: JK Stray girl}

1 Caller: $\quad$ I juss thought (.) 'no: ahm not doin this'.

Becuz ${ }^{\circ}$ u- uh-॰ (.) w- when she came te me befo:re, $>$ w-she wuz in a terr'ble state. $<$ 
8

9

10

11

12 CPO:

13

14 a:fterwards people- (.) neighbours 'ad said they'd seen 'er out in the rain=she wouldn' let' $m$ in the house:=she g- Mum goes a bit strange someti:mes, $=$ um[:

[.hh So you've her-

you've hear:d sort've corroborative stories about the things that she's tol:d you.

The recalibration repair seems designed to expose the credibility of her informants: persons who live close enough to witness what is happening - and do so routinely and recurrently - are a reliable source of corroborating information about the girl's situation. "Neighbors" can serve as "unmotivated, yet concerned" eyewitnesses, whereas "people" seems like a rather anonymous and thus possibly suspect source. Here, the shift from "people" to a membership category exploits the inference-rich character of these terms. This makes available to the $\mathrm{CPO}$ call taker how the reported source could come to have the claimed knowledge, and thus constitutes a way to increase the credibility of that source. In this way, the recalibration reveals a practical epistemological basis (Whalen and Zimmerman, 1990) for her report - one designed to bolster the caller's request for help with this matter. In other words, the recalibration exposes the relationship of the referent to the ascribed action in order to strengthen the action accomplished through the description. (Also see the discussion of Extract 6 above.)

\section{Explaining Rejection in an Offer Sequence}

In Extract 17, reference recalibration seems directly implicated in the action being implemented by the turn in which the repair occurs. In this case, Tess is offering to help Bea who 
is organizing a card party at her home. She offers to bring silverware (line 1), but is turned down by Bea (line 3). Bea then goes on to explain her rejection in terms of a possible silverware shortage that won't be a problem.

Extract 17: SBL 2:6

\begin{tabular}{|c|c|c|}
\hline 1 & Tes: & $=$ Dih you [need inny sill[ver. \\
\hline 2 & Bea: & {$[\mathrm{hhhhh}(0.2)$} \\
\hline 3 & & Uh: no buhcuz I'll:: \\
\hline 4 & & {$\left[\mathrm{u} \mathrm{h}^{\circ} * \mathrm{u}^{\circ}\right]$} \\
\hline 5 & Tes: & 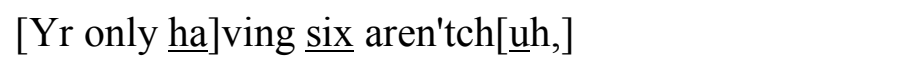 \\
\hline 6 & Bea: & [Eh-] No $\underline{\text { I'm having }}$ \\
\hline 7 & & te-e:n. \\
\hline 8 & Bea: & hh hhhhhhh \\
\hline 9 & & $(0.3)$ \\
\hline 10 & Bea: & u-But uh:m hhh \\
\hline 11 & & $(0.3)$ \\
\hline 12 & Bea: & i-See four fer bri:dge'n six fer: (1.0) Tripoly. \\
\hline 13 & & (.) \\
\hline 14 & Tes: & . hh (.) Oh ye:::(s). \\
\hline 15 & & $(0.2)$ \\
\hline 16 & Bea: & 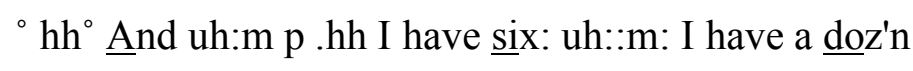 \\
\hline 17 & & teaspoons, 'n ulotta people don't like to: uh hh \\
\hline 18 & & I find some'v my friends don't like tih use dessert \\
\hline 19 & & spoons anywa:y,= \\
\hline
\end{tabular}


$20 \quad$ Tes: $\quad=\downarrow \underline{I}[\mathrm{know} \underline{\mathrm{it}}, \uparrow]$

21 Bea: [ $\quad[\mathrm{h} \mathrm{h} \mathrm{h} \mathrm{h} \mathrm{]} \mathrm{so} \mathrm{ah'll} \mathrm{püt} \mathrm{out} \mathrm{the} \mathrm{dessert} \mathrm{spoons}$

As part of her explanation, Bea begins to claim that "a lot of people don't like to [use dessert spoons]" (line 17). This formulation appeals to "common knowledge about people in general." In the course of her explanation, Bea changes this to "I find some of my friends don't like..." (line 18). The repair solution exposes a relationship between Bea and the referent and explicitly lays claim to firsthand knowledge of the recalibrated reference as the basis of her rejection. The reformulated reference ("some of my friends") is tailored to the action Bea's turn implements: accounting for rejecting the offer. This relational membership category ("my friends") both strengthens her epistemic claim to firsthand knowledge ("I find") and - because members of this category would be the beneficiaries of Tess's offer - it is their use of dessert spoons that is most proximately relevant as an evidential basis for rejecting the offer.

\section{$\underline{\text { Recalibration Beyond Reference To Persons }}$}

As we noted at the outset, recalibration repairs are not limited to the formulation of references to persons, but can operate on other types of formulations. In this section, we examine a recalibration repair to an object formulation that narrows the scope of the reference. In Extract 18 , the repair narrows a reference to a motor vehicle and this can be understood to intensify the action that is being formed up in the turn. Bella is explaining why she is reluctant to resume her driving lessons. One of her reasons is a minor car accident she had experienced several months 
prior to this conversation. In the following, Bella works to present the accident as a traumatic event, thereby legitimizing it as a reason for her decision to give up driving.

\section{Extract 18: RP3 (Russian)}

1 BEL: Ja vot- 1:etom ezdila na da,chu/ I PRT summer went to dacha In the summer I drove to the dacha

mne m: zerkalo- .hh nu mashịna tak blizka me mirror PRT car so close and my mirror- a vehicle went by so close

3 ka mne prae,xala:/=eta tre:jler agromnyj/ da?,/ to me went_by that trailer huge right to me/ a huge semi-trailer truck, right

4 RIM: $\mathrm{Hm} \mathrm{mm}$,

5 BEL: shto vot z-zerkalo bakavoe sbila/=da, / that PRT mirror side torn-off yes that it tore off my side mirror, right

$6 \quad=\left[\mathrm{i}\right.$ voschem: (.) ja tak dazhe sabrazi $\underline{1}, \mathrm{t}^{\prime}=$ and generally I so even realize and so I didn't even

$7 \quad$ RIM: $\quad[\mathrm{Hmm}$

8 BEL: $=$ ne uspela $/=\mathrm{a}$ patom padumala/ not have-time PRT then thought have time to realize but then I thought

9 Nichë sebe/ eschë by bukval'na pjat' santime,trav/ imagine self more PRT literally five centimeters Oh my god/ literally another five centimeters

.hh on by nas za kak dvinul v kjuve,t/

it PRT us so threw in ditch and it would have run us into the ditch

In describing her accident, Bella first uses the word "mashina" (line 2), which, in Russian, is a generic term that can refer to any motor vehicle of any size with at least four wheels - from a car 
to a large truck. When Bella reaches a possible completion of the preliminary component of her compound TCU (after "a vehicle went by so close to me" at lines 2 - 3), which projects a "shto..." ("that...") clause (cf. Lerner, 1991), she suspends the forward trajectory of her telling to specify what kind of motor vehicle it was: "a huge semi-trailer truck" (or "an articulated lorry" in British English). In other words, she recalibrates a generic reference to "machina" ("a motor vehicle") by replacing it with a more differentiated reference to "tre:jler agromnyj" ("a huge semi-trailer truck"). Bella then resumes her telling at line 5 (about the side mirror being torn off by the passing truck) and then describes her strong emotional reaction to this experience (lines 6 - 10). The recalibration repair is consequential for Bella's interactional project: specifically, the more detailed formulation ("a huge semi-trailer truck") serves to intensify the shock of the accident, and thus validates Bella's decision to give up driving as a result of the experience.

\section{Broadening the Scope of a Formulation}

The preceding sections described some of the ways narrowing a formulation can be employed. In this final section, we turn to recalibration repairs that broaden the scope of a reference. We have divided our report in this way because there is evidence that these two modes of recalibration repair (those that narrow a reference and those that broaden it) are not equivalent forms of action that differ only in the direction of the recalibration; rather, they seem to operate as asymmetrical alternatives, with repairs that narrow the scope of a formulation operating as a "preferred" and more commonly employed variety, whereas ones that broaden the scope operate as a "dispreferred" and appreciably less common variety. In the former, a speaker appears to embrace a more precise formulation (and thereby increases its situated relevance for the task-athand), whereas in the latter case a speaker begins with a formulation that is well-fitted to the 
task-at-hand, but then seems to back away from it. ${ }^{10}$ The latter form of recalibration repair is, evidently, a rather more accountable (and accounted for) action than the former.

Broadening a formulation can be employed to aggregate one category of person with another category, as in Extract 8 (shown above) where "women" is replaced with "people actually" at the beginning of the interviewer's question. This repair broadens the class of persons from "women who want to work after retirement age" - a formulation well-fitted to the setting ("Women's Hour" radio program) and topic - to one that might be considered inapposite or unexpected (see Clift, 2001, on the uses of TCU-final “actually”).

In addition, broadening the scope of a formulation is a method for downgrading the certainty with which a same referent is proffered. ${ }^{11}$ In Extract 19 a composite categorical reference, "teenage sons" (line 4) is reduced to the simple categorical reference "teenagers" (line 6) thereby setting gender aside.

\section{Extract 19: SBL 1:12.2}

1 A: And so she called one day an was talking, =and s-

2 she said, "Oh Bea" (could uh) .hh "will you: uh: ${ }^{\circ} \mathrm{m}-$

3 (0.4) in your prayers remember (.) .hh our son, an

4 daughter in la:w, $=$ their three: teenage: ${ }^{\circ} \mathbf{s}[::$ ] $]$ sons

5 B:

$[\mathrm{Mm}]$

6 A: I think it is, $(0.2)$ or three teenagers $($ anyway, $)=$

$7 \mathrm{~B}: \quad=\mathrm{Mm} \mathrm{hm}$,

8 A: They've just moved someplace, 
Notice that the repair completion is preceded by an explicit declaration of uncertainty ("I think it is"; line 6) and is followed by a token ("anyway") that seems to indicate the speaker is backing away from a more precise formulation and settling for a less precise one.

In Extract 20 (previously shown as Extract 4), a caller to a birth crisis helpline reports a problem with a previous birth that resulted in paralysis in her foot. She had assumed this was related to a badly administered epidural anesthetic, but had subsequently come to doubt that in light of an independent report. Here the repair broadens the reference from "anaesthetist" to “doctor" (lines 3 - 4), thereby shifting from a member of a collection of kinds of doctors to the name of the (superordinate) collection. Then the caller accounts for this reformulation by noting that referring to the doctor as an "anaesthetist" is only a presumption (line 4), thereby explicitly claiming a degree of uncertainty.

\section{Extract 20: BCC02}

1 Brenda: $\quad<$ I can't afford to pay prị:vately .hhhh but what they have

2

3

4

5

6 done is got an independent report from an anaesthetist, .hhhh U:m An' this anaesthetist:

or doctor $>$ I sup-presume he's an anaesthetist $<$ uhm has said .hh that's it's not necessarily the epidu:ral ((swallows)) it might in fact just be because I had a long labour

Here the recalibration (along with the account for it) displays a reduced certainty about the caller's knowledge of the referent. Brenda is taking the doctor's report seriously and assuming it carries the authority that warrants this, but in recalibrating the reference in this way, she can also be seen as obliquely questioning the authority of the source of the report and thus perhaps indirectly questioning the report she is so worried about. (See Extracts 6 and 16 for cases where 
narrowing the scope of a reference is apparently used to increase the legitimacy of the referent.) In both Extracts 19 and 20, the speaker relaxes the categorical fit to better reflect "what they know." Moreover, in Extract 20 this seems to be exploited to accomplish something beyond displaying the speaker's uncertainty.

As with repairs that narrow a formulation, broadening the scope of a formulation is not limited to person reference. In Extract 21, a place formulation, "Brooklyn," (one of New York City's boroughs) is replaced by the encompassing formulation, "New York" (line 3). This recalibration repair is a way for this Russian speaker to display her uncertainty about the location of the home cleaning service (for the elderly) they are discussing.

\section{Extract 21: I 4}

1 Mom: $\quad$ Est' takoj s:ervis/

is such service

There is such service

2

(.)

3 Mom

${ }^{\circ}($ nu v eta $) \mathbf{v}$ Brukline/ $\mathbf{v}$ Nju Jorke $>$ ja n'znaju $<>^{\circ}$ PRT in that in Brooklyn in New York I not-know (in that) in Brooklyn in New York $>$ I don't know<

4

5 Mom: $\quad \uparrow$ Ani toka prixodjat ubirat'/ they only come to-clean They only come to clean

Again, as in Extracts 19 and 20, notice that immediately following the repair solution ("New York"), the speaker goes on to explicitly state her lack of certainty about the location of the service (">I don't know<"; line 3), thus accounting for her moving away from the more precise place formulation. 
In Extracts 19 to 21 the recalibration repair broadens the scope of a formulation to display speaker uncertainty. However, on some occasions this form of recalibration can be employed to adjust to recipient uncertainty. In Extract 22, an exchange among members of a Russian immigrant family, Mom and Dad are addressing their daughter Lena. When Lena (who moved to the US as a small child) visibly displays non-recognition (line 4) of a place formulation ("Tallinn"), Dad attributes the problem to Lena's limited knowledge of the relevant geography, in that he replaces the problematic formulation with the encompassing formulation "in Estonia" (line 6).

\section{Extract 22: I6b}

\begin{tabular}{|c|c|c|}
\hline 1 & MOM: & $\begin{array}{l}\mathrm{V} \mathrm{Ta}[\text { line ani zhivut/ ((to Ilana)) } \\
\text { in Ta[llinn they live }\end{array}$ \\
\hline 2 & DAD: & $\begin{array}{l}\text { [V TALINE ((off camera)) } \\
\text { in Tallinn }\end{array}$ \\
\hline 3 & MOM: & $\begin{array}{l}\text { V Taline/ ((to Ilana)) } \\
\text { in Tallinn }\end{array}$ \\
\hline 4 & & (1.0) ((Lena makes a confused face) \\
\hline 5 & LEN: & {$\left[{ }^{\circ}\right.$ What $?^{\circ}$} \\
\hline 6 & DAD: & $\begin{array}{l}\text { [V Esto:ni:i/ ((off camera)) } \\
\text { in Estonia }\end{array}$ \\
\hline
\end{tabular}

In this case, a display of recipient uncertainty can be found in Lena's facial expression (line 4) and Dad's subsequent reference recalibration can be understood as responsive to this expression, and therefore as aimed at repairing trouble in the recipient design of the place formulation. 


\section{Concluding Remarks}

In its broadest strokes this report investigates what can be involved in the selection of one evidently more suitable form of reference over another evidently less suitable one. This investigation brings into relief what "suitability" consists of in and as the practical action of talking in interaction. We demonstrate that, in addition to operating in the domain of description (Schegloff, 2000), granularity-like considerations operate in the domain of reference to persons (and extend to other types of formulations as well). We have shown that self-initiated repair of non-recognitional person reference can enable consequential shifts in the precision of a reference. These are not the shifts in the "texture" of descriptions that was Schegloff's focus, but rather they are, in a sense, shifts in the "inferential texture" bound to categorical references - and thus involve a rather different order of granularity considerations.

One key finding here is that narrowing and broadening the scope of a formulation do not seem to be symmetrical alternatives. This is evidenced by the fact that repairs that narrow and broaden a reference are employed differently: narrowing the scope of a categorical reference is routinely employed to tailor a reference to the action of a turn, whereas broadening it is routinely employed to tailor the formulation to the knowledge state of a speaker (by displaying speaker uncertainty). In addition, broadening a reference is routinely accompanied by explicit accounts for the recalibration, whereas the categorical tailoring achieved through narrowing a formulation is itself a self-evidently (or reflexively) accountable action.

This finding, that narrowing and broadening a reference are differentially accountable in practice, may bring to mind the formal pragmatic constraints introduced by Grice (1989). ${ }^{12}$ Specifically, Grice's maxim of quality (“do not say what you believe to be false or you lack adequate evidence for") is flouted by speakers offering information that is more precise than they 
can support. Repairing a formulation in the direction of decreased precision constitutes a mechanism by which a speaker can retract an initial, unsupportable claim - and consistent with Grice's reasoning, speakers themselves account for this form of recalibration in terms of their lack of adequate knowledge. When precision and certainty cannot both be satisfied in an exchange, then one might ask, is it certainty that is relaxed to satisfy precision, or instead, is it precision that is relaxed to satisfy certainty? When Grice (1989: 32-33) entertained the possibility that these two maxims might "clash" (i.e. when both cannot be simultaneously satisfied), he posited a circumstance in which quantity would give way to quality - and our evidence suggests that it is the maxim of quantity that is relaxed in favor of satisfying the maxim of quality, insofar as it is those recalibrations that broaden a reference (and overtly violate quantity in doing so) that require an explanation which appeals to quality. By contrast, repairing a formulation in the direction of increased precision is in concert with Grice's maxim of quantity ("make your contribution as informative as is required for the current purposes of the exchange, and not more so"), but does not bring quality into question. Speakers routinely shift from broader, less informative formulations to ones that are better fitted to the exchange and its purposes - and do so with no accounting for the shift.

Finally, by describing a practice in which the further development of a turn or sequence is suspended in order to tailor a formulation, our findings provide access to members' own "membership categorization analysis." By examining the workings of reference recalibration repair, we open a window that exposes members' practical understandings of the operation of the actions and inferences associated with membership categorization devices. Describing these practices allows us to expose what members' knowledge amounts to in practice. 


\section{References}

Bolden, G., Mandelbaum, J., \& Wilkinson, S. (2012). Pursuing a response by repairing an indexical reference. Research on Language and Social Interaction, 45:2.

Clift, R. (2001). Meaning in interaction: The case of actually. Language, 77:2, 245-291.

Couper-Kuhlen, E., \& Thompson, S. A. (2005). A linguistic practice for retracting overstatements: Concessive repair. In A. Haulinen and M. Selting (Eds.) Syntax and lexis in conversation (pp. 257-288). Amsterdam: Benjamins.

Drew, P. (2003). Precision and exaggeration in interaction. American Sociological Review, $68,917-938$.

Grice, P. (1989). Studies in the way of words. Cambridge, Mass.: Harvard University Press. Heritage, J. (2002). The limits of questioning: Negative interrogatives and hostile question content. Journal of Pragmatics, 34, 1427-1446.

Jefferson, G. (1985). On the international unpackaging of a 'gloss'. Language in Society, 14, 435-466.

Land, V., \& Kitzinger, C. (2007). Some uses of third-person reference forms in speaker selfreference. Discourse Studies, 9(4), 493-525.

Lerner, G. H. (1991). On the syntax of sentences in progress. Language in Society, 20, 441-458.

Lerner, G. H. \& Kitzinger, C. (2007). Extraction and aggregation in the repair of individual and collective self-reference. Discourse Studies, 9, 526-557.

Lerner, G. \& Kitzinger, C. (2010). Repair prefacing: Preparing the way for same-turn self-repair. Paper presented at the International Conference on Conversation Analysis, Mannheim, Germany, July, 2010. 
Pomerantz, A. (1984). Giving a source or basis: The practice in conversation of telling 'how I know'. Journal of Pragmatics, 8, 07-625.

Sacks, H. (1972a). An initial investigation of the usability of conversational data for doing sociology. In Sudnow, D. (Ed.), Studies in social interaction (pp. 31-74). New York: Free Press.

Sacks, H. (1972b). On the analyzability of stories by children. In J.J. Gumperz \& Hymes, D. (Eds.), Directions in sociolinguistics: the ethnography of communication (pp.325-345). New York: Rinehart \& Winston.

Sacks, H. (1992). Lectures on conversation [2 vols.]. Oxford: Basil Blackwell.

Sacks, H., \& Schegloff, E. A. (1979). Two preferences in the organization of reference to persons in conversation and their interaction. In G. Psathas (Ed.), Everyday language: Studies in ethnomethodology (pp. 97-121). New York: Irvington Publishers.

Schegloff, E. A. (1972). Notes on a conversational practice: Formulating place. In D. N. Sudnow (Ed.), Studies in social interaction (pp. 75-119). New York: Macmillan, The Free Press.

Schegloff, E. A. (1987). Recycled turn beginnings: A precise repair mechanism in conversation's turn-taking organization. In G. Button \& J. R. E. Lee (Eds.), Talk and social organization (pp. 70-85). Philadelphia: Multilingual Matters.

Schegloff, E. A. (1996). Some practices for referring to persons in talk-in-interaction: a partial sketch of a systematics. In B. A. Fox (Ed.), Studies in Anaphora (pp. 437-485). Philadelphia: John Benjamins Publishing.

Schegloff, E. A. (2000). On granularity. Annual Review of Sociology, 26, 715-20.

Schegloff, E. A. (in press). Ten operations in self-initiated, same-turn repair. In J. Sidnell, 
M. Hayashi \& G. Raymond (Eds.) Conversational Repair and Human Understanding . Cambridge University Press.

Stivers, T. (2007). Alternative recognitionals in person reference. In N. J. Enfield \& T. Stivers (Eds.), Person reference in interaction: Linguistic, cultural, and social perspectives (pp. 73-96). Cambridge: Cambridge University Press.

Whalen, M. \& Zimmerman, D. (1990). Describing trouble: Practical epistemology in citizen calls to the police. Language in Society, 19: 465-492.

Wilkinson, S. and Weatherall, A. (2011). Insertion repair. Research on Language and Social Interaction, 44, 65-91. 


\section{Notes}

${ }^{1}$ See Sacks (1992, Vol. I, pp. 752-763, and especially Vol. II, pp. 19-20) for early considerations of "fitting a reference to the topic at hand" and "word co-selection in storytelling," respectively. Also relevant here is Sacks's (1992, Vol. I pp. 417-420 and p. 544) discussion of "misidentification" as a way of doing an action. By contrast, although Schegloff (1972: 80) notes that, "it would be foolhardy to try to excerpt from its conversational surroundings some particular formulation, and examine how it was selected out of a set of terms," he goes on to characterize both Sacks's work on membership categories and his own on place formulations as having been usefully carried out "in temporary isolation from topical context" - "given the current state of investigation [at the time]." More recently, Schegloff (1996) and others (Land and Kitzinger, 2007 on self-reference and Stivers, 2007 on recognitional reference) have begun to describe how reference forms "can display (or constitute) ... the current relevance with which the referent figures in the talk" (Schegloff, 1996: 447).

${ }^{2}$ The speaker thereby treats the original formulation as not having been precise enough, rather than e.g. targeting the silence as indicating reluctance of the part of England to respond. See Bolden, Mandelbaum and Wilkinson (this issue) for a discussion of repairs used to pursue a response in this way.

3 Jefferson's (1985) examination of “defensive detailing" and the later exposing of an apparent (innocuous) detail as having been a gloss for a delicate matter that is then specified might stand as an early explication of the operation of granularity. 
${ }^{4}$ For example, Schegloff illustrates a storyteller's move from projecting a gloss for something that was said in the scene he is describing to presenting a rendition of the utterance itself. He notes that this kind of calibration of levels of granularity marks a shift in the development of the narrative as it approaches its climax, suggesting a relationship between shifts in granularity (e.g. moving from coarser to finer forms of description) and the trajectory of a narrative.

${ }^{5}$ These constitute the majority of our cases - a fact consistent with the observation that replacing very likely constitutes the single most common same-turn repair operation in talk-in-interaction. ${ }^{6}$ Here, our concern with the recalibration of references to persons intersects with the work of Wilkinson and Weatherall (2011). Their investigation of insertion repairs found that one action inserting can be used to accomplish is specifying the trouble source. However, as they note and our investigation confirms, the action of specifying is not insertion-specific and, at least in the domain of reference to persons, seems to be predominantly carried out through replacement repairs.

${ }^{7}$ See Lerner and Kitzinger (2007) for a discussion of extraction and aggregation in terms of speaker self-reference repair.

${ }^{8}$ The fact that she has earlier lamented not having heard from her husband's co-workers in Norfolk may explain the recalibration repair (shifting from “one 'r two people $\downarrow$ in Norfolk." to "frie:nds"; line 3), since it distinguishes friends from the co-workers mentioned earlier, extracting them from the broader reference to "people," thus making clear that the persons in Norfolk from whom they have heard are not those delinquent co-workers, but rather, incumbents of a different relationship category: "friends." 
${ }^{9}$ The overlap of "people" with Skip's response (lines 9 and 10) furnishes a systematic basis for retrieval of the overlapped talk and this provides an opportunity for selecting another term. In this case the post-overlap talk is composed as more than retrieval - it is formed up as a revision ("sort of acquaintances").

${ }^{10}$ See Drew (2003) and Couper-Kuhlen \& Thompson (2005) for other practices aimed at backing away from something that has been claimed, but in these cases speakers are backing away from exaggerated claims in a manner that produces more precise ones.

${ }^{11}$ It is for those recalibration repairs that retain a same referent that we have observed this asymmetry.

${ }^{12}$ We would like to acknowledge John Heritage for suggesting this association to us. 